\title{
Androgenic-Anabolic Steroid (Boldenone) Abuse as a Cause of Dilated Cardiomyopathy
}

Eran Kalmanovich*, Sa'ar Minha, Marina Leitman, Zvi Vered and Alex Blatt

Assaf Harofeh Medical Center, Aviv University, Israel

"Corresponding author: Eran Kalmanovich, Department of Cardiology, Assaf Harofeh Medical Center, Zerifin, Sackler School of Medicine, Tel Aviv University, Israel, Tel: +972-50-5191121; E-mail: kalmanovicheran@gmail.com

Received date: Feb 27, 2014, Accepted date: Mar 27, 2014, Published date: Apr 3, 2014

Copyright: (c) 2014 Kalmanovich E, et al. This is an open-access article distributed under the terms of the Creative Commons Attribution License, which permits unrestricted use, distribution, and reproduction in any medium, provided the original author and source are credited.

\section{Case Presentation}

A 34-year old, previously healthy male, presented to the ER with worsening dyspnea over a period of three weeks and the appearance of blood tinged sputum. Soon after presentation, the patient was hypoxemic and required mechanical ventilation. Chest X-ray demonstrated bilateral infiltrates and he was admitted to the ICU with the tentative diagnosis of acute respiratory distress syndrome. Investigation by PICCO, Suggested the presence of heart failure were and the patient was transferred to the ICCU. On admission, the patient maintained normal blood pressure but still needed mechanical support with high $\mathrm{FiO}_{2}$ values to maintain adequate oxygenation. Physical examination was remarkable for his muscular appearance. The heart sounds were regular. The lungs were clear to auscultation, although chest X-ray revealed signs of pulmonary edema. Blood count was remarkable for hemoglobin of $21 \mathrm{gr} / \mathrm{dl}$ with hematocrite of $65 \%$. His blood chemistry showed creatinine level on $1.74 \mathrm{mg} / \mathrm{dL}$, with no electrolytes imbalance. LFT were normal, total protein and albumin levels were normal, elevated CK with normal TnT. CRP $10 \mathrm{mg} / \mathrm{L}$ (normal level $<10 \mathrm{mg} / \mathrm{L}$ ). Blood cultures and panel of common respiratory infections were all negative. ECG showed normal sinus rhythm, with $\mathrm{p}$ pulmonale, signs of hypertrophy and inverted $\mathrm{T}$ waves in chest leads. Swan-gantz Cather measurements revealed cardiac output (CO) 3.9, capillary wedge pressure $34 \mathrm{mmHg}$, SVR 2070 and CI 2.2 consistent with cardiogenic shock. Transthoracic echocardiography demonstrated severe global dysfunction (left ventricular ejection fraction $=20 \%$ ) with severely dilated left ventricle $5.1 \mathrm{~cm}$ (end-systolic diameter), asymmetric hypertrophy (Septum $14 \mathrm{~mm}$, Posterior wall 12 $\mathrm{mm}$ ). Minimal mitral and tricuspid regurgitation were also noted (Table 1 and Figure 1).

During his admission a coronary angiography was preformed, demonstrating normal coronaries arteries. Meticulous repeated history obtained from the patient's family yielded that he had been a kick boxer and a bodybuilder. After asking for all the supplements the patient was taking to be brought to our attention, a vial of Boldenone, an androgenic anabolic steroid (AAS) usually used in veterinary medicine was found. It turned out that the patient was using this illicit drug for his bodybuilding needs. After treating his failing heart, the patient was discharged for outpatient follow-up. During 1 year of follow-up he was treated with a combination of beta-blockers, ACEi and aldactone antagonist according to heart failure guidelines recommendations, with no further admission for either cardiac or non-cardiac causes. Within few months, his cardiac function was partially recovered (EF-40\%), also demonstrating improvement in left ventricular chamber measurements and withdrawal of his hypertrophy (Table 1), thus establishing the reversibility of the drug effect-

\begin{tabular}{|c|c|c|}
\hline & At admission & 1-year follow up \\
\hline $\mathrm{EF} \%$ & $20 \%$ & $40 \%$ \\
\hline LA diameter $(\mathrm{mm})$ & 3.9 & 3.8 \\
\hline LA area $\left(\mathrm{cm}^{2}\right)$ & 14.0 & 20 \\
\hline LVEDD (cm) & 6.1 & 5.6 \\
\hline LVESD $(\mathrm{cm})$ & 5.1 & 3.3 \\
\hline IVS (mm) & 14.0 & 9.0 \\
\hline $\mathrm{PW}(\mathrm{mm})$ & 12 & 9.0 \\
\hline Right atrium & Normal & Normal \\
\hline Rt. Ventricule & Normal & Normal \\
\hline $\begin{array}{l}\text { Estimated Pulmonary } \\
\text { Pres. }(\mathrm{mmHg})\end{array}$ & $\mathrm{n} / \mathrm{a}$ & 25 \\
\hline Aortic root & 3.0 & 2.9 \\
\hline Ascending Aorta & $\mathrm{n} / \mathrm{a}$ & 2.7 \\
\hline
\end{tabular}

Table 1: Echocardiography measurements.

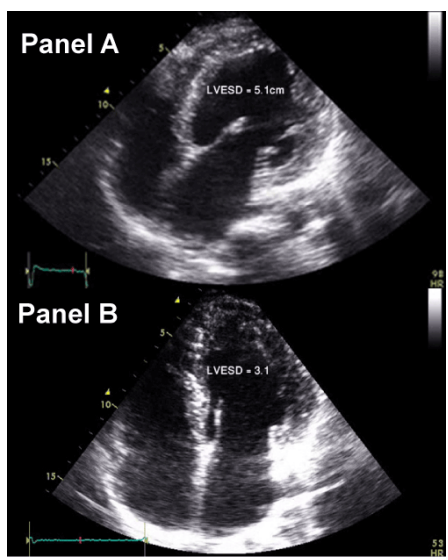

Figure 1: Echocardiographic Transthoracic.

Panel A on admission, showing severe LV dysfunction

Panel B 1year follow up with improvement of LV function 


\section{Discussion}

The use of illicit performance-enhancing supplements is common among both professional athletes and high school students. Many of the supplements have no proven merits but are associated with serious adverse reactions [1]. As its name suggests, AAS has two distinct yet overlapping effects: anabolic, promoting cell growth, and androgenicenhancing masculine characteristics. AAS anabolic effect increase cellular protein synthesis and this result in buildup of tissue especially in muscles. AAS exert their influence on the myocytes through androgen receptor leading to left ventricular hypertrophy and dilation, and impaired contraction and relaxation [3-5]. Echocardiographic studies have shown that supraphysiologic doses of AAS lead to both morphologic and functional changes of the heart. These include a tendency to produce myocardial hypertrophy, a possible increase of heart chamber diameters, unequivocal alterations of diastolic function and ventricular relaxation, and most likely a subclinically compromised left ventricular contractile function [6].

AAS abuse has previously been associated with various cardiovascular adverse events including acute myocardial infarction, pulmonary embolism, dilated cardiomyopathy, arrhythmia and sudden death [8-19].

Boldenone undecylenate is a testosterone analogue used in veterinary medicine as an anabolic steroid. Trade names include Equipoise, Parenabol, Equigan and Ultragan [7]. It is used to improve the growth and food conversion in food-producing animals. In most countries worldwide, this anabolic steroid is forbidden for human uses and meat production as it had been developed for veterinary use. Due to an extremely long half-life of this drug, positive results for steroid use can show up for up to 1.5 years. Although long half-life, some case series suggest that even severe changes are at least partially reversible, after discontinuing from AAS and using therapy to prevent or reverse further remodelling.

In the case presented, infection was probably not the cause of his heart failure, his medical history in the days before his admission was not suggestive for infection, on admission there were no signs of infection, either in physical examination, laboratory exams and chest $\mathrm{X}$-ray. Blood cultures and panel of common respiratory infections were all negative. Ischemic reason was excluded due to demonstration of normal coronary arteries on angiography. Also, the negative TnT levels in repeated exams during his first admission exclude the possibility of myocardial injury to either ischemic or viral infection. Other possible reasons as secondary metabolic or nutritional deficiency are less likely due to the age of the patient (34 year old on his admission), the fact that there were no pre-existing diseases as liver cirrhosis or chronic renal failure and last his nutritional status on admission were normal and no signs on malabsorption. Last, his remarkable recovery of in heart function does not follow the course of viral myocarditis or ischemic cause, but more the removal of the offending agent (Boldenone).

This case presentation emphasizes two important messages: the first is that major clues for the diagnosis, especially in obscure cases, can be drawn from meticulous history taking. The second message relates to the hazards of the increasing incidence of usage of illicit drugs, mainly anabolic steroids in young adults. We hope that awareness and education will prevent further cases.

\section{References}

1. Jenkinson DM, Harbert AJ (2008) Supplements and sports. Am Fam Physician 78: 1039-1046.

2. McEwan IJ (2013) Androgen receptor modulators: a marriage of chemistry and biology. Future Med Chem 5: 1109-1120.

3. Keller ET, Ershler WB, Chang C (1996) The androgen receptor: a mediator of diverse responses. Front Biosci 1: d59-71.

4. Heinlein CA, Chang C (2002) Androgen receptor (AR) coregulators: an overview. Endocr Rev 23: 175-200.

5. Fragkakia AG, Angelisa YS, Koupparis M, Tsantili-Kakoulidouc A, Kokotosd G, et al. (2009) Structural characteristics of anabolic androgenic steroids contributing to binding to the androgen receptor and to their anabolic and androgenic activities. Applied modifications in the steroidal structure. Steroids 74: 172-197.

6. Paul Vanberg, Dan Atar (2010) Androgenic Anabolic Steroid Abuse and the Cardiovascular System. Doping in Sports: Biochemical Principles, Effects and Analysis. Handbook of Experimental Pharmacology 195: 411-457.

7. http://www.micromedexsolutions.com.assafhez.medlcp.tau.ac.il/ micromedex2/librarian/ND_T/evidencexpert/ND_PR/evidencexpert/CS/ D34C7A/ND_AppProduct/evidencexpert/DUPLICATIONSHIELDSYNC/ 802668/ND_PG/evidencexpert/ND_B/evidencexpert/ND_P/ evidencexpert/PFActionId/evidencexpert.IntermediateToDocumentLink? docId $=3720 \&$ contentSetId $=35 \&$ title $=$ BOLDENONE + UNDECYLENATE\&servicesTitle $=$ BOLDENONE+UNDECYLENATE

8. Appleby M, Fisher M, Martin M (1994) Myocardial infarction, hyperkalaemia and ventricular tachycardia in a young male body-builder. Int J Cardiol 44: 171-174.

9. Fisher M, Appleby M, Rittoo D, Cotter L (1996) Myocardial infarction with extensive intracoronary thrombus induced by anabolic steroids. Br J Clin Pract 50: 222-223.

10. Godon P, Bonnefoy E, Guérard S, Munet M, Velon S, et al. (2000) [Myocardial infarction and anabolic steroid use. A case report]. Arch Mal Coeur Vaiss 93: 879-883.

11. Halvorsen S, Thorsby PM, Haug E (2004) [Acute myocardial infarction in a young man who had been using androgenic anabolic steroids]. Tidsskr Nor Laegeforen 124: 170-172.

12. Lyngberg KK (1991) [Myocardial infarction and death of a body builder after using anabolic steroids]. Ugeskr Laeger 153: 587-588.

13. Stergiopoulos K, Brennan JJ, Mathews R, Setaro JF, Kort S (2008) Anabolic steroids, acute myocardial infarction and polycythemia: a case report and review of the literature. Vasc Health Risk Manag 4: 1475-1480.

14. Fineschi V, Riezzo I, Centini F, Silingardi E, Licata M, et al. (2007) Sudden cardiac death during anabolic steroid abuse: morphologic and toxicologic findings in two fatal cases of bodybuilders. Int J Legal Med. 121: 48-53.

15. Sullivan ML, Martinez CM, Gallagher EJ (1999) Atrial fibrillation and anabolic steroids. J Emerg Med 17: 851-857.

16. Lau DH, Stiles MK, John B, Shashidhar, Young GD, et al. (2007) Atrial fibrillation and anabolic steroid abuse. Int J Cardiol 117: e86-87.

17. Figueredo VM (2011) Chemical cardiomyopathies: the negative effects of medications and nonprescribed drugs on the heart. Am J Med 124: 480-488.

18. Achar S, Rostamian A, Narayan SM (2010) Cardiac and metabolic effects of anabolic-androgenic steroid abuse on lipids, blood pressure, left ventricular dimensions, and rhythm. Am J Cardiol 106: 893-901.

19. Ahlgrim C, Guglin M (2009) Anabolics and cardiomyopathy in a bodybuilder: case report and literature review. J Card Fail 15: 496-500. 